\title{
The legacies of SARS - international preparedness and readiness to respond to future threats in the Western Pacific Region
}

\author{
John S Mackenzie ${ }^{a b}$ and Angela Merianos ${ }^{c}$ \\ Correspondence to John S Mackenzie (e-mail: J.Mackenzie@curtin.edu.au).
}

\section{THE SEVERE ACUTE RESPIRATORY SYNDROME (SARS) OUTBREAK}

It is now 10 years since the world was faced with the first severe and readily transmissible new disease of the 21 st century - severe acute respiratory syndrome (SARS). Unknown and unrecognized, it emerged in late 2002 as the probable cause of an outbreak of atypical pneumonia in Guangdong Province, southern China. It then spread to Hong Kong (China) via an infected traveller who arrived at his hotel on 21 February 2003 where he infected 15 other guests. They, in turn, travelled to other countries carrying the new disease and initiating outbreaks in Viet Nam, Singapore and Canada. Three weeks later, with increasing numbers of cases among hospital staff in Hong Kong (China) and Viet Nam, the World Health Organization (WHO) issued a global alert on 12 March 2003 about this new acute respiratory syndrome of unknown etiology. However, the disease was spreading rapidly along major air routes, prompting WHO to issue an emergency travel advisory on 15 March, as well as naming the new disease "severe acute respiratory syndrome" and providing the first surveillance case definition. ${ }^{1}$ The disease continued to spread, reaching 26 countries on five continents and causing at least 8096 cases and 774 deaths worldwide before it was finally contained. ${ }^{2}$ The SARS epidemic had a dramatic effect on the global economy leading to serious economic losses, collapse of regional tourism and travel industries and substantial declines in the gross national product of affected countries. ${ }^{3}$ While actual figures for the cost of the outbreak vary and depend on different interpretations, the approximate cost was believed to approach US\$ 40 billion.
The global response to SARS was unprecedented and provided a new way of working internationally, using real-time electronic communication. ${ }^{4}$ The response was coordinated by WHO from its headquarters in Geneva and its Western Pacific Regional Office in Manila with assistance from its country offices and from the many partners in the Global Outbreak Alert and Response Network (GOARN). ${ }^{5,6}$ WHO established real-time information sharing among networks of virologists, clinicians and epidemiologists who communicated through daily teleconferences and video conferences, virtual grand rounds and via secure web sites. Their goal was to: (1) expedite the identification of the etiological agent and development of diagnostic reagents; ${ }^{7-9}$ (2) share clinical information, including presenting features, disease progression, treatment and prognostic indicators; and (3) describe the key epidemiological features of this novel disease, including the evolution of the epidemic, transmission dynamics and risk factors for the disease; ${ }^{10}$ and later, the effectiveness of control measures.

Under WHO's leadership, the work of these networks supported the global implementation of effective prevention and control strategies even before the agent of SARS was identified. The SARS epidemic was contained by applying basic public health principles of disease control: enhanced surveillance; early case detection and triage; patient isolation; the tracing, monitoring and home isolation of their contacts; enhanced hospital infection control; and raising public awareness about the disease and its prevention. These efforts were assisted by the natural history of infection with SARS coronavirus $(\mathrm{CoV})$, which differed from other respiratory viruses, as

\footnotetext{
Faculty of Health Sciences, Curtin University, Perth, Western Australia, Australia.

Burnet Institute, Melbourne, Australia.

Consultant in Infectious Diseases Epidemiology, Sydney, Australia

doi: 10.5365/wpsar.2013.4.2.009
} 
its transmission was greatest when illness was most severe and asymptomatic transmission was rare. Thus evidence-based control measures were reinforced while other measures, such as the quarantine of well contacts, were relaxed. ${ }^{11}$

On 5 July 2003, WHO was able to declare the end of the epidemic, although some additional cases were later described from laboratory accidents in Singapore, Taipei and Beijing, and four sporadic cases of SARS were reported from Guangdong between December 2003 and January 2004. Although the origin of the novel SARS-CoV remains an enigma, it is probable that the source of infection was small mammals in the live animal markets in Guangdong Province, China, where a wide variety of wildlife species, including Himalayan palm civets, Chinese ferret-badgers and raccoondogs, were kept in overcrowded conditions with poor biosecurity. ${ }^{12}$ Seroprevalence studies in live animal traders in Guangzhou demonstrated significantly higher exposure to SARS-CoV compared to controls, especially in those who traded primarily in masked palm civets. The SARS-CoV strain responsible for the global epidemic was similar to virus isolates obtained from small mammals sampled in live animal markets, especially civets, but differed significantly from them by having a 29 base-pair deletion in ORF8 that created a novel sublineage. ${ }^{12}$ In response to these findings, China issued a ban on the hunting and sale of civets (lifted in August 2003) and improved biosecurity in civet farms and within live animal markets. More recently, increasing evidence has indicated insectivorous bats as the natural reservoir for SARS-CoV. ${ }^{13,14}$

WHO declared that the last outbreak of SARS was contained on 18 May 2004 and there has been no evidence of SARS-CoV infection in humans since that time.

\section{LESSONS LEARNT FROM THE SARS OUTBREAK}

Several important lessons were learnt from the SARS outbreak. It provided a clear demonstration that a previously unknown pathogen could emerge at any time and in any place and, without warning, threaten the health, well-being and economies of all societies. SARS also demonstrated: (1) that countries must have the capability and capacity to maintain an effective alert and response system to detect and quickly react to outbreaks of international concern and to share information about such outbreaks rapidly and transparently; (2) that responding to pandemic threats requires global cooperation and global participation; and (3) that a global alert and response network is needed to provide technical assistance when national disease control systems are stressed beyond their capacity. ${ }^{15}$ SARS also warned that wildlife may be the reservoirs of novel pathogens and that animal surveillance activities must be coordinated with human surveillance as a One Health response.

The response to SARS clearly showed the relevance and importance of the GOARN to WHO's outbreak response capability. GOARN had been created by WHO in 2000 as a partnership with technical institutions and networks to improve the coordination of international outbreak responses and to provide an operational framework to focus the delivery of support to countries. Previously all deployments had been to single country outbreaks, but in responding to SARS, deployments were made to several countries, significantly helping with outbreak assistance and surge capacity.

\section{REVISION OF THE INTERNATIONAL HEALTH REGULATIONS}

Perhaps the most important legacy from the SARS epidemic was the additional urgency and focus given to the revision of the International Health Regulations (IHR) by the World Health Assembly. ${ }^{16,17}$ The revised IHR (2005), adopted by the World Health Assembly in May $2005,{ }^{18}$ came into force on 15 June 2007, providing the legal framework for the collective responsibility of countries, WHO and other intergovernmental organizations for global health security. Signatories are obligated to develop core public health capacities for alert, risk assessment and outbreak response and to inform WHO, through national IHR focal points, of any event with the potential to spread or extend beyond their borders. Countries were given a five-year period in which to implement the new Regulations; although if they had not achieved compliance in all core capacities by 2012 , they were able to request a two-year extension. Many countries failed to meet the 2012 deadline, and have requested a two-year extension.

Since the adoption of IHR (2005), the world has witnessed several emergent zoonoses including the geographical expansion of highly pathogenic 
avian influenza $\mathrm{A}(\mathrm{H} 5 \mathrm{~N} 1),{ }^{19}$ the emergence of a novel coronavirus in the Arabian peninsula in 2012-2013, ${ }^{20,21}$ and a low pathogenic avian influenza $A(H 7 N 9)$ in China in $2013^{22,23}$ - three viruses causing severe, often fatal, human respiratory disease. The world also experienced the H1N1 pandemic in 2009; an estimated 284400 influenza-related deaths, with 9.7 million years of life lost, occurred during the 16 months of this pandemic of moderate severity (April 2009-August 2010). ${ }^{24}$

These examples clearly demonstrate the need to link human disease surveillance and response activities with those for animal diseases if we are to detect potential outbreaks of zoonotic diseases early and in time to limit spread. Building on their individual tracking, verification and alert mechanisms, the World Organization for Animal Health (OIE), the Food and Agricultural Organization of the United Nations (FAO) and WHO launched the Global Early Warning System in 2006 for predicting and responding to zoonoses. An exciting new global early warning system is also being developed to detect novel zoonotic emerging diseases that move from wildlife to humans. The PREDICT program is run by the United States Agency for International Development Emerging Pandemic Threats Program and is coordinated through the University of California and Columbia University with partners in the Americas, Africa and south-eastern Asia, including China, Laos, Cambodia, Viet Nam, Malaysia, Thailand and Indonesia. Using a new 'SMART' surveillance method (Strategic, Measurable, Adaptive, Responsive, Targeted) designed to detect novel diseases with pandemic potential early, it is hoped that PREDICT will give health professionals an opportunity to prevent the further spread of a new zoonotic disease. ${ }^{25}$

\section{ASIA PACIFIC STRATEGY FOR EMERGING DISEASES}

To assist Member States in the Western Pacific and South-East Asia regions to meet the core capacities requirements of IHR (2005), a joint plan known as the Asia Pacific Strategy for Emerging Diseases (APSED) was developed. ${ }^{26}$ APSED had five principal objectives: (1) to reduce the risk of emerging diseases; (2) to strengthen the early detection of outbreaks of emerging diseases; (3) to strengthen the early response to emerging diseases; (4) to strengthen preparedness for emerging diseases; and (5) to develop sustainable technical collaboration in the Asia Pacific region. Not surprisingly at the time, the threat posed by $\mathrm{H} 5 \mathrm{~N} 1$ highly pathogenic avian influenza was the major focus that drove the activities and planning in APSED and that laid the foundations for building up the core capacities required by IHR (2005). It also demonstrated the importance of the intersectoral collaboration in partnership with OIE and FAO. While surveillance, early detection and rapid response are the keys to reducing the threats from emerging diseases, an understanding of the mechanisms of emergence are also essential in planning and preparedness. ${ }^{27}$

The first APSED (2005) was so successful in meeting its objectives, with event-based surveillance systems and trained rapid response teams able to quickly conduct field investigations established in most countries, that a second, updated strategy, APSED (2010), ${ }^{28}$ has been initiated to consolidate gains made in the first five years. While APSED (2010) continues to focus on emerging diseases, it has expanded its scope to eight focus areas and also to include other public health threats. At the same time, given the demographic, socioeconomic and political diversity of the 48 countries and areas of the Asia Pacific Region, there is a greater realization that implementation of APSED must be responsive to the individual situation and context in each country.

\section{CHALLENGES FOR THE FUTURE}

There have been major achievements in health security during the past decade since the world faced the potential SARS pandemic. Implementation of IHR (2005) has been a crucial step in this progress and stimulated new ways of working across sectors, within and between countries, and in partnership with WHO, and with other inter-governmental organizations and nongovernmental organizations. This has led to the rapid and transparent sharing of information on diseases of international public health concern; supported by an increased knowledge of the mechanisms and origins of disease emergence, transmission and modes of spread it has provided us with a much more effective and rapid ability to detect and respond to future threats.

Nevertheless, there remains a long way to go. Not only are nearly half of the countries in the Asia Pacific region still developing their IHR (2005) core capacities, with some possibly requiring additional time, but the region has been the epicentre for many emerging infectious diseases. More than half of the world's population live in the Asia Pacific region, providing many 
challenges in building, strengthening and sustaining functional national systems and capacities for managing emerging diseases. The world is still facing the ongoing threat from avian influenza $A(H 5 N 1)$ and from new diseases such as the novel coronavirus in the Middle East and $A(H 7 N 9)$ avian influenza in China. Doubtless, new threats will emerge in the near future. The importance of IHR (2005) in detecting and responding to these threats in a transparent, collaborative and coordinated way cannot be overestimated; it is the single most important development in public health in this new millennium.

\section{Conflicts of interest}

None declared.

\section{Funding}

None.

\section{References:}

1. World Health Organization. Severe acute respiratory syndrome (SARS). Weekly Epidemiological Record, 2003, 78:81-83. PMID:12701272

2. Global Alert and Response (GAR). Summary of probable SARS cases with onset of illness from 1 November 2002 to 31 July 2003 (based on data as of the 31 December 2003). Geneva, World Health Organization, 2003 (http://www.who.int/csr/sars/country/ table2004_04_21/en/, accessed 9 May 2013).

3. Wong YCR, Siu A. Counting the economic cost of SARS. In: Peiris M, Anderson LJ, Osterhaus ADME, Stohr K, Yuen KY, eds. Severe Acute Respiratory Syndrome. Oxford, Blackwell Publishing, 2005, 213-230.

4. Heymann DL. The international response to the outbreak of SARS in 2003. Philosophical Transactions of the Royal Society of London. Series B, Biological Sciences, 2004, 359:11271129.

5. SARS: how a global epidemic was stopped. Geneva, World Health Organization, $2006 \quad$ (http://whqlibdoc.who.int/ wpro/2006/9290612134_eng.pdf, accessed 9 May 2013).

6. Mackenzie JS et al. The WHO response to SARS, and preparations for the future. In: Knobler S, Mahmoud A, Lemon S, Mack A, Sivitz $\mathrm{L}$, Oberholtzer K, eds. Learning from SARS: preparing for the next disease outbreak. Washington, DC, Institute of Medicine, National Academies Press, 2004, 42-50.

7. Peiris JSM et al.; SARS study group. Coronavirus as a possible cause of severe acute respiratory syndrome. Lancet, 2003, 361:1319-1325. doi:10.1016/S0140-6736(03)130772 pmid: 12711465

8. Ksiazek TG et al.; SARS Working Group. A novel coronavirus associated with severe acute respiratory syndrome. The New England Journal of Medicine, 2003, 348:1953-1966. doi:10.1056/NEJMoa030781 pmid:12690092

9. Drosten $\mathrm{C}$ et al. Identification of a novel coronavirus in patients with severe acute respiratory syndrome. The New England Journal of Medicine, 2003, 348:1967-1976. doi:10.1056/ NEJMoa030747 pmid:12690091
10. Department of Communicable Disease Surveillance and Response. Consensus document on the epidemiology of severe acute respiratory syndrome (SARS). Geneva, World Health Organization, 2003 (http://www.who.int/csr/sars/en/WHOconsensus.pdf, accessed 9 May 2013).

11. Merianos A. Severe acute respiratory syndrome. In: Heymann D, ed. Control of Communicable Diseases Manual, $19^{\text {th }}$ Edition. Washington, DC, American Public Health Association, 2008.

12. Guan $Y$ et al. Isolation and characterization of viruses related to the SARS coronavirus from animals in southern China. Science, 2003, 302:276-278. doi:10.1126/science.1087139 pmid: 12958366

13. Lau SK et al. Severe acute respiratory syndrome coronaviruslike virus in Chinese horseshoe bats. Proceedings of the National Academy of Sciences of the United States of America, 2005, 102:14040-14045. doi:10.1073/pnas.0506735102 pmid:16169905

14. Li W et al. Bats are natural reservoirs of SARS-like coronaviruses. Science, 2005, 310:676-679. doi:10.1126/science.1118391 pmid: 16195424

15. Heymann DL, Mackenzie JS, Peiris M. SARS legacy: outbreak reporting is expected and respected. Lancet, 2013, 381:779-781. doi:10.1016/S0140-6736(13)60185-3 pmid:23668493

16. World Health Assembly. Revision of the International Health Regulations. Resolution WHA56.28. Geneva, World Health Organization, 2003 (http://apps.who.int/gb/archive/pdf_files/ WHA56/ea56r28.pdf, accessed 3 May 2013).

17. World Health Assembly. Severe acute respiratory syndrome. Resolution WHA56.29. Geneva, World Health Organization, 2003 (http://apps.who.int/gb/archive/pdf files/WHA56/ea56r29. pdf, accessed 3 May 2013).

18. International Health Regulations (2005). Geneva, World Health Organization, 2005 (http://whqlibdoc.who.int/ publications/2008/9789241580410_eng.pdf, accessed 3 May 2013).

19. Capua I, Marangon S. Control and prevention of avian influenza in an evolving scenario. Vaccine, 2007, 25:5645-5652. doi:10.1016/j.vaccine.2006.10.053 pmid:17169466

20. Novel coronavirus summary and literature update - as of 25 April 2013. Geneva, World Health Organization, 2013 (http://www.who.int/csr/disease/coronavirus_infections/update20130425/en/index/html, accessed 9 May 2013).

21. The Health Protection Agency (HPA) UK Novel Coronavirus Investigation Team. Evidenceofperson-to-persontransmission within a family cluster of novel coronavirus infections, United Kingdom, February 2013. Euro Surveillance: European Communicable Disease Bulletin, 2013, 18(11):pii:20427 (http://www. eurosurveillance.org/ViewArticle.aspx?Articleld $=20427$, accessed 9 May 2013).

22. Gao $R$ et al. Human infection with a novel avian-origin influenza A (H7N9) virus. The New England Journal of Medicine, 2013, 368:1888-1897. doi:10.1056/NEJMoa1304459 pmid:23577628

23. Chen $Y$ et al. Human infections with the emerging avian influenza A H7N9 virus from wet market poultry: clinical analysis and characterisation of viral genome. [Epub ahead of print]. Lancet, 2013,381:1916-1925. doi:10.1016/S0140-6736(13)60903-4 pmid:23623390

24. Dawood FS et al. Estimated global mortality associated with the first 12 months of 2009 pandemic influenza A H1N1 virus circulation: a modelling study. The Lancet Infectious Diseases, 2012, 12:687-695. doi:10.1016/S1473-3099(12)70121-4 pmid:22738893 
25. Morse SS et al. Prediction and prevention of the next pandemic zoonosis. Lancet, 2012, 380(9857): 1956-1965. doi:10.1016/ S0140-6736(12)61684-5 pmid:23200504

26. Asia Pacific Strategy for Emerging Diseases (2005). Manila, World Health Organization Regional Office for the Western Pacific, 2005 (http://www.wpro.who.int/emerging_diseases/documents/ APSED_final_endorsed_and_edited_by_EDT-map_removed FORMAT-20/en/index.html, accessed 9 May 2013).
27. Mackenzie JS. Responding to emerging diseases: reducing the risks through understanding the mechanisms of emergence. Western Pacific Surveillance and Response, 2011, 2:1-5. doi:10.5365/ wpsar.2011.2.1.006

28. Asia Pacific Strategy for Emerging Diseases (2010). Manila, World Health Organization Regional Office for the Western Pacific, 2011 (http://www.wpro.who.int/emerging_diseases/APSED2010/ en/, accessed 3 May 2013). 